\title{
Celebrities and Shoes on the Female Brain: The Neural Correlates of Product Evaluation in the Context of Fame
}

\section{Mirre Stallen, Ale Smidts, Mark Rijpkema, Gitty Smit, Vasily Klucharev, and Guillén Fernández}

To appear in Journal of Economic Psychology

\begin{tabular}{|l|l|}
\hline \multicolumn{2}{|l|}{ ERIM REPORT SERIES RESEARCHINMANAGMENT } \\
\hline ERIM Report Series reference number & ERS-2009-048-MKT \\
\hline Publication & August 2009 \\
\hline Number of pages & 23 \\
\hline Persistent paper URL & http://hdl.handle.net/1765/16583 \\
\hline Email address corresponding author & m.stallen@donders.ru.nl \\
\hline Address & Erasmus Research Institute of Management (ERIM) \\
& RSM Erasmus University / Erasmus School of Economics \\
& Erasmus Universiteit Rotterdam \\
& P.O.Box 1738 \\
& 3000 DR Rotterdam, The Netherlands \\
& Phone: $\quad+31104081182$ \\
& Fax: $\quad+31104089640$ \\
& Email: info@erim.eur.nl \\
& Internet: $\quad$ www.erim.eur.nl \\
\hline
\end{tabular}

Bibliographic data and classifications of all the ERIM reports are also available on the ERIM website: www.erim.eur.nl 


\section{ERASMUS RESEARCH INSTITUTE OF MANAGEMENT}

\section{REPORT SERIES}

\section{RESEARCH IN MANAGEMENT}

\begin{tabular}{|l|l|}
\hline ABSTRACT AND KEYWORDS \\
\hline Abstract & $\begin{array}{l}\text { Celebrity endorsement is omnipresent. However, despite its prevalence, it is unclear why } \\
\text { celebrities are more persuasive than (equally attractive) non-famous endorsers. The present } \\
\text { study investigates which processes underlie the effect of fame on product memory and purchase } \\
\text { intention by the use of functional magnetic resonance imaging methods. We find an increase in } \\
\text { activity in the medial orbitofrontal cortex (mOFC) underlying the processing of celebrity-product } \\
\text { pairings. This finding suggests that the effectiveness of celebrities stems from a transfer of } \\
\text { positive affect from celebrity to product. Additional neuroimaging results indicate that this positive } \\
\text { affect is elicited by the spontaneous retrieval of explicit memories associated with the celebrity } \\
\text { endorser. Also, we demonstrate that neither the activation of implicit memories of earlier } \\
\text { exposures nor an increase in attentional processing is essential for a celebrity advertisement to } \\
\text { be effective. By explaining the neural mechanism of fame, our results illustrate how } \\
\text { neuroscience may contribute to a better understanding of consumer behavior. }\end{array}$ \\
\hline Free Keywords & $\begin{array}{l}\text { celebrity endorsement, persuasion, medial orbital frontal cortex, affect transfer, neuromarketing, } \\
\text { neuroeconomics }\end{array}$ \\
\hline Availability & $\begin{array}{l}\text { The ERIM Report Series is distributed through the following platforms: } \\
\text { Academic Repository at Erasmus University (DEAR), DEAR ERIM Series Portal } \\
\text { Social Science Research Network (SSRN), SSRN ERIM Series Webpage } \\
\text { Research Papers in Economics (REPEC), REPEC ERIM Series Webpage }\end{array}$ \\
\hline Classifications & $\begin{array}{l}\text { The electronic versions of the papers in the ERIM report Series contain bibliographic metadata } \\
\text { by the following classification systems: } \\
\text { Library of Congress Classification, (LCC) } \underline{\text { LCC Webpage }} \\
\text { Journal of Economic Literature, (JEL), JEL Webpage } \\
\text { ACM Computing Classification System CCS Webpage } \\
\text { Inspec Classification scheme (ICS), ICS Webpage }\end{array}$ \\
\hline
\end{tabular}


Celebrities and shoes on the female brain: The neural correlates of product evaluation in the context of fame

Mirre Stallen $^{\mathrm{a}, \mathrm{b}, *}$, Ale Smidts ${ }^{\mathrm{a}}$, Mark Rijpkema ${ }^{\mathrm{b}}$, Gitty Smit ${ }^{\mathrm{b}}$, Vasily Klucharev ${ }^{\mathrm{a}, \mathrm{b}}$, Guillén

Fernández ${ }^{\text {b,c }}$

a - Rotterdam School of Management, Erasmus University, the Netherlands

b - Donders Institute for Brain, Cognition and Behaviour, Radboud University Nijmegen, the Netherlands

c - Department of Neurology, Radboud University Nijmegen Medical Centre, the Netherlands

* - Corresponding author: M.Stallen@donders.ru.nl 


\begin{abstract}
Celebrity endorsement is omnipresent. However, despite its prevalence, it is unclear why celebrities are more persuasive than (equally attractive) non-famous endorsers. The present study investigates which processes underlie the effect of fame on product memory and purchase intention by the use of functional magnetic resonance imaging methods. We find an increase in activity in the medial orbitofrontal cortex (mOFC) underlying the processing of celebrity-product pairings. This finding suggests that the effectiveness of celebrities stems from a transfer of positive affect from celebrity to product. Additional neuroimaging results indicate that this positive affect is elicited by the spontaneous retrieval of explicit memories associated with the celebrity endorser. Also, we demonstrate that neither the activation of implicit memories of earlier exposures nor an increase in attentional processing is essential for a celebrity advertisement to be effective. By explaining the neural mechanism of fame, our results illustrate how neuroscience may contribute to a better understanding of consumer behavior.
\end{abstract}




\section{Introduction}

The use of celebrities as endorsers in product advertising is popular. Over the last twentyfive years, the number of advertisements relying on a famous presenter has increased considerably (Pringle and Binet, 2005). Nowadays, the typical format of a celebrity print advertisement is straightforward: Brad Pitt for Tag Heuer watches, George Clooney for Nespresso, or Kate Moss for Rimmel cosmetics; just pairing the face of a famous individual with a brand seems to do the trick. No explicit and extensive message appears required to convince the consumer of the qualities of the advertised product only because the product has been associated with a celebrity.

Consumer research has indeed shown that celebrity endorsement may enhance the recall of advertising messages, increase the recognition of brand names and make advertisements more believable (Friedman and Friedman, 1979; Kamins et al., 1989; Petty et al., 1983). However, whether celebrities are also able to improve purchase intentions is less clear. Some studies reported that commercials using celebrities did enhance consumers' likelihood of buying the advertised brand (Heath et al., 1994; Ohanian, 1991; Petty et al., 1983), whereas others were not able to demonstrate such an effect (see Erdogan, 1999). Recent research by Rossiter and Smidts (Rossiter and Smidts, in review) suggested that the underlying cause of these contrasting findings is that the majority of these studies did not take the perceived expertise of the celebrity for the endorsed product into account. They posited that for persuasion, consumers need to identify the presenter as having technical knowledge about the advertised product or as being an experienced user of it. A follow-up neuroimaging study supported this hypothesis by demonstrating that a single exposure to an expert celebrity with a product indeed resulted in a long-lasting positive effect on memory and purchase intention for the product, whereas exposure to a non-expert celebrity endorser did not (Klucharev et al., 2008). Examination of the brain mechanisms underlying this persuasive effect of expertise indicated that an expert context induced feelings of trust towards the product and increased semantic elaboration of the celebrity-product association, leading to a deeper encoding of the product in memory. Moreover, this research showed that the brain does assess the expertise of a celebrity very rapidly and without explicit endorsement (Klucharev et al., 2008).

\section{The present study}

The work by Klucharev and coworkers (2008) on the neurobiological account of expertise illustrates the relevance of neuroscientific methods for consumer research as this study specified more precisely which processes underlie the persuasive effect of expertise than would 
have been possible with the use of behavioral methods alone. The aim of the present study was to increase the understanding of celebrity endorsement even further by examining which processes underlie the persuasive effect of fame.

Given the large fees popular celebrities are asking for endorsements, advertisers need to understand what the added value is of a celebrity endorser compared to a non-famous one. Earlier research on celebrity endorsement explained the effectiveness of celebrities in terms of a conditioning process: the pairing of a positively valenced stimulus (a celebrity) with an initially neutral stimulus (a product) results in a transfer of affect from the valenced to the neutral stimulus (from celebrity to product) (Till et al., 2008; Walther et al., 2005). However, this evaluative conditioning account does not elaborate on why the perception of a celebrity results in the experience of positive affect.

One explanation we suggest is that the perception of a famous face may bring to mind facts (e.g. a celebrity's latest movie) and personal episodes (e.g. a movie night with friends) that are related to the presenter. These memories will be inherently positive since celebrity endorsers are generally selected because of their popularity and associations with nice events. The positive affect that is experienced during the retrieval of these memories may subsequently be transferred to the product associated with the celebrity.

Another (non-exclusive) explanation is that the perception of a celebrity face triggers the retrieval of implicit memories, i.e. memories that are independent of conscious remembering (Schacter, 1987; Schacter and Buckner, 1998). Earlier exposure to a stimulus has been shown to be sufficient to increase the positive affect experienced toward that stimulus at a later moment (Harmon-Jones and Allen, 2001; Zajonc, 2001). Because consumers have obviously been exposed more often to the face of a celebrity than to that of an unknown endorser, implicit memories of earlier exposures to a celebrity may cause consumers to experience more positive feelings during exposure to a famous person than when perceiving a non-famous presenter.

Both explanations above describe a celebrity endorser as being a positively valenced stimulus. However, some influential psychological frameworks have conceptualized emotion along two dimensions: valence (how positive or negative) and arousal (how exciting or calm) (Bradley et al., 1992; Russell, 1980). Possibly, a celebrity endorser does not only elicit the experience of positive affect, but is perceived to be more arousing than an unknown endorser as well. If this is true, we expect celebrity advertisements to receive more attention than advertisements with unknown presenters since arousing stimuli are known to be processed with more attention than non-arousing ones (e.g. LaBar et al., 2000). The increase in attention towards a celebrity advertisement may enhance the depth of processing of the product-celebrity paring 
and in turn facilitate the retrieval of explicit memories linked to the celebrity. As the retrieval of explicit memories may be important to establish a transfer of positive affect from celebrity to product, attention may play an important role during celebrity endorsement situations. A recent study by Pleyers and colleagues (in press) indicated that attention is indeed of importance for the process of affect transfer. They found that the conditioning of products with positively valenced stimuli was sensitive to the amount of attentional resources available.

In sum, the goal of the present study was threefold. First, we examined whether the conditioning account of celebrity endorsement was supported by the neural activity underlying the encoding of a product in the context of fame, i.e. whether the brain areas involved indicated a process of affect transfer. Second, we investigated whether the positive affect associated with a celebrity resulted from the retrieval of explicit facts and episodes, from the retrieval of implicit memories, or from the retrieval of explicit and implicit memories together. And third, we explored the role of arousal-driven-attention in celebrity endorsement.

\section{Neural correlates}

To investigate the underlying processes of the persuasive effect of celebrity endorsers, we designed an experiment imitating the typical format of a celebrity advertisement: showing a famous face together with a product without any explicit persuasive message. While their brain activity was being recorded with a functional magnetic resonance imaging (fMRI) scanner, we presented young female subjects with photographs of equally attractive famous and non-famous faces together with photos of products.

First of all, as the orbitofrontal cortex has been shown to encode the learning of associations between neutral and reinforcing stimuli (Rolls and Grabenhorst, 2008), we hypothesized to find increased activity in the orbitofrontal cortex when presenting products together with a celebrity face. As, according to the conditioning account of fame the perception of a celebrity gives rise to positive emotions, a celebrity face may function as a reinforcing stimulus whereas the product is a neutral stimulus. In particular, we expected to find an increase in activity in the medial part of the orbitofrontal cortex during the encoding of stimulus-reinforcement associations between a famous face and a product, as the medial orbitofrontal cortex has been correlated with the subjective liking of several rewarding stimuli (Beer et al., 2008; Grabenhorst et al., 2008; Plassmann et al., 2008; Rolls et al., 2009), whereas the lateral part has been more often linked to the evaluation of negative reinforcers (Kringelbach, 2005; Kringelbach and Rolls, 2004; Rolls and Grabenhorst, 2008). 
To examine whether the positive affect experienced upon the perception of a celebrity endorser is the result of the retrieval of explicit knowledge related to the famous endorser or the result of earlier exposures to the celebrity face (i.e. implicit memories), we compared the neural activation patterns underlying the presentation of a famous face with the brain activity related to the presentation of a non-famous face. If the retrieval of explicit memories is important for the experience of positive affect, we expected famous faces to induce either more extensive activations in brain regions associated with the retrieval of factual knowledge, also classified as semantic knowledge (e.g. remembering an endorser's latest hit movie), or in brain areas associated with the retrieval of episodic memories, which are context-specific memories that are unique to each individual (e.g. remembering what happened after you saw that specific endorser's movie) (Tulving, 1972; Wiggs et al., 1999). In case the perception of a celebrity triggers both the retrieval of semantic and episodic memories, both memory networks will be activated during the presentation of a famous face. Retrieving semantic information, as compared to episodic experience, has been shown to activate consistently the superior prefrontal cortex and middle temporal gyrus, predominantly in the left hemisphere (Simons and Spiers, 2003; Wiggs et al., 1999). The retrieval of episodic memories has mainly been associated with an increase in activity in the left parietal and medial prefrontal cortex, and the medial temporal lobe (Maguire, 2001; Wagner et al., 2005).

Instead of eliciting affect by the activation of explicit knowledge, celebrity endorsers may be experienced as more rewarding because of their implicit familiarity to consumers. If celebrity endorsers indeed evoke the experience of positive affect due to earlier exposures, we expected exposure to a famous face to elicit activity in the striatum, as previous studies showed that this area is responsive to the reward value associated with a face (Aharon et al., 2001; Kampe et al., 2001).

We also tested the hypothesis that celebrities would enhance attentional processing because they are more arousing than unknown endorsers. Past research has suggested that processing in higher-order visual cortex in the occipital lobe and the inferior temporal cortex is modulated by attentional processing (Kanwisher and Wojciulik, 2000). Thus, if celebrities enhance the depth of processing of an advertisement, we expected to find an increase in activity in these brain regions during the presentation of a celebrity endorser. 


\section{The experiment}

\subsection{Participants}

Twenty-six right-handed Dutch females (mean age 20.6 years) participated in the experiment. Subjects received a financial compensation of 24.5 euros ( \pm 32 dollars) for participation. As familiarity with celebrities was essential for the present study, subjects were selected using a questionnaire screening their interest in celebrities and fashion. All subjects reported to be healthy, on no medication and free from any history of neurological or psychiatric illness, head trauma or drug abuse. Written informed consent was obtained from each subject according to the local medical ethics committee. Data of the first three subjects had to be discarded due to problems with the response recording during scanning, resulting in 23 subjects for final analyses.

\subsection{Stimuli}

Twenty digital color portraits of international and Dutch female celebrities (movie-, music and TV-stars) and 20 digital color portraits of non-famous females were selected from publicly available internet sources. Only female presenters were selected to prevent any effects of gender on subjects' perception of the photograph. Furthermore, attractiveness between the celebrities and non-famous females was matched based on attractiveness ratings by 6 young females not used as subjects in the further experiment. Four hundred and eighty digital photos of female shoes were collected from publicly available internet sources as products. Choosing shoes as products was optimal for two reasons. First, they are present in a large variety in an everyday shopping context. This is important to prevent any effects due to specific outlying items. Second, as women in general (and not celebrities only) are regarded to be experienced users of shoes (Belk, 2003), the presentation of shoes as products should prevent any confounding effects of expertise on the fame manipulation. From the 480 pictures of shoes two sets of 240 stimuli were created. One set was used for the fMRI session and a behavioral memory test performed after scanning; the other set was only used as filler items in the following behavioral memory test. Stimuli set presentation was counterbalanced, so that across subjects all stimuli appeared equally often as a filler in the memory task as they were used in the fMRI session. All photographs were similar in terms of overall complexity, contrast, brightness and pixel width. Pixel height varied for the pictures of shoes due to the height of the shoes: boots gave larger pixel height than flat shoes. 


\section{3 fMRI Paradigm}

In the scanner, subjects were shown 20 blocks with a female celebrity and 20 blocks with a non-famous female. These blocks appeared in random order and each block consisted of seven trials. During the first trial of each block, a face appeared randomly on the right or left side of the screen with a name presented next to it. For the famous faces, the actual first and last name of the celebrity was given. For the non-famous faces, names were created by combining general first and last names. As both Dutch and international celebrities were shown to the subjects, the names of the non-famous females corresponded to typical Dutch or foreign female names as well.

During the six following trials of each block, the female face remained on the screen, and instead of the name a shoe appeared next to the face (see figure 1). The presentation of shoes was randomized so that there were no fixed shoe-face combinations across subjects. In total, subjects were shown 120 trials in which a shoe was paired with a celebrity face and 120 trials in which a shoe was paired with a non-famous face.

While being scanned, subjects were instructed to indicate by appropriate button press whether they thought that the shoe on the screen was owned by the female shown next to it or not. This orientation task aimed to focus subjects' attention and to promote subjects to link the two stimuli together. As a cover story subjects were instructed that 50 percent of all 240 shoes shown were identical to shoes truly owned by the presented famous and non-famous females. This implicated that, on average, for each presented female face there were three shoes possessed by this female (since every female face was shown in combination with six shoes). The aim of this instruction was to balance response behavior between trials showing a celebrity face and trials showing a non-famous face. Subjects were explained that for the shoes possessed by celebrities we selected pictures showing shoes that were highly similar to shoes celebrities had been wearing on press photos. Shoes owned by non-famous females were told to be selected by these females themselves. In addition, to enhance motivation, subjects were instructed to pay close attention to the shoes as their memory performance would be assessed and rewarded (with a maximum of doubling the standard compensation) in a following behavioral session. Subjects responded by pressing with their right middle or index finger on a response box. Mean intertrial interval (ITI) was $10 \mathrm{~s}$ (range 7-13 s) and stimuli duration was $1 \mathrm{~s}$. Total scan time was approximately 55 minutes.

\subsection{Behavioral measures}

After scanning, subjects performed two behavioral tasks, one regarding the shoes and one regarding the faces. Subjects initially did a recognition memory test and a purchase intention 
assessment of the previously seen shoes. During the recognition memory test, subjects were exposed to a sequence of pictures containing a random mixture of the 240 shoes processed inside the scanner, only this time without the presentation of a face photograph, and 240 new previously unseen shoes. Subjects were offered two response options (i) picture seen before and (ii) picture not seen before. Purchase intention of the shoes was measured by asking subjects to make an estimate of purchase incidence and indicate it on a scale from 0 to 100 percent (in steps of 10). To assess the recognition memory performance we compared the overall proportion of hits (percentage of previously seen shoes that was correctly identified as recognized: hits / (hits + misses) * 100) with the overall proportion of false alarms (percentage of new shoes that was falsely identified as recognized: false alarms / (false alarms + correct rejections) * 100). Recognition performance was above chance if the proportion of hits was larger than the proportion of false alarms.

During the second behavioral task, subjects evaluated all 20 famous and 20 non-famous faces seen in the fMRI session on physical attractiveness and familiarity. Attractiveness ratings were made on an 11-point scale ranging from 0 to 100 (in steps of 10) with 0 standing for 'not attractive' and 100 indicating 'very attractive'. Familiarity of the faces was measured using a binary response scale with the options 'familiar' and 'not familiar'. To make sure all celebrities were liked and none of the celebrities elicited negative emotions, subjects indicated their liking of the celebrities on a scale from 0 to 100 (in steps of 20) with 0 indicating 'not at all' and 100 indicating 'very'. All trials in the behavioral tasks were presented in a self-paced manner with a stimulus duration of 1 second.

\subsection{MRI acquisition parameters}

Functional images were acquired with a 1.5T Siemens Sonata scanner with ascending slice acquisition and a T2*-weighted echo-planar imaging (EPI) sequence (TR $2.29 \mathrm{~s}$, TE $30 \mathrm{~ms}$, flip angle $70^{\circ}$, slice matrix $64 \times 64 \mathrm{~mm}$, slice thickness $3.0 \mathrm{~mm}$, slice gap $0.5 \mathrm{~mm}$, FOV 224 $\mathrm{mm}$ ). Anatomical scans were acquired with a T1-weigthed MP-RAGE sequence (176 sagittal slices, volume TR 2.25 s, TE 3.93 ms, flip angle $15^{\circ}$, slice matrix $256 \times 256$, slice thickness 1.0 mm, no gap, FOV 256 mm).

\section{6 fMRI data analysis}

Data were preprocessed and analyzed using standard software (SPM5, Wellcome Department of Cognitive Neurology London). The first 5 volumes of each subjects' EPI sequence set were discarded to allow for longitudinal relaxation time equilibration. The remaining images 
were realigned to the first volume. Functional images were corrected for motion and differences in slice time acquisition. Next, images were normalized to the Montreal Neurological Institute (MNI) template using parameters defined from the normalization of the anatomical scan to the MNI template and images were smoothed with a Gaussian kernel of $8 \mathrm{~mm}$ full-width at halfmaximum to reduce noise. Motion parameters were stored and used as so-called nuisance variables in the general linear model (GLM) analysis.

A random-effects analysis within the framework of the general linear model was applied to model event-related responses. Four regressors were defined for each subject based on the onsets of the relevant trials: 'Celebrity Face', 'non-Famous Face', 'Shoe with Celebrity Face', and, 'Shoe with non-Famous Face'. Regressors were modeled with a canonical hemodynamic response function and a general linear model analysis was used to create contrast images summarizing differences in brain activity across the Shoe with Celebrity Face and Shoe with nonFamous Face conditions as well as differences in brain activity across the Celebrity Face and non-Famous Face conditions. With these images, two group average contrast SPM maps were created: The Object contrast map showed what brain activity was underlying the processing of an object in the context of a famous face (Shoe with Celebrity Face > Shoe with non-Famous Face) and the Face contrast map showed what brain activity was underlying the processing of a famous face without the presence of an object (Celebrity Face > non-Famous Face). To see whether different brain areas were involved in the processing of an object in the context of a famous face and in the processing of a famous face alone, we performed an additional statistical test comparing the brain activity present in the Object contrast map with the activity pattern present in the Face contrast map $(\mathrm{P}<.05$ uncorrected). This exclusive masking procedure revealed only activity in the Object contrast map that did not overlap with the brain areas involved in the Face contrast map. All statistical analyses were thresholded at the cluster-level with a $\mathrm{P}<.001$ uncorrected.

\section{Results}

\subsection{Behavioral results}

Manipulation check

Although the pictures of famous and non-famous females were selected based on equal attractiveness ratings, post-scan results revealed that the famous females $(\mathrm{M}=65.1 \%$, s.d. $=$ 7.3\%) were perceived as being slightly more attractive than the non-famous females ( $M=60.5 \%$, s.d. $=7.8 \%)\left(\mathrm{t}_{(22,1)}=2.7, p=.014\right)$. To eliminate a confounding effect of physical attractiveness on the fame manipulation, four faces (24 trials per subject) were removed from further analyses. 
Removal of the two famous faces that received the highest score on attractiveness together with the two non-famous faces that received the lowest score on attractiveness resulted in equal attractiveness ratings $\left(\mathrm{M}_{\text {famous }}=64.0 \%\right.$, s.d. $=7.6 \% ; \mathrm{M}_{\text {infamous }}=61.4 \%$, s.d. $=7.9 \% ; \mathrm{t}_{(22,1)}=1.5, p$ $=.15$ ). The mean attractiveness rating of the 36 remaining faces was $63 \%$ (s.d. $=6.4 \%$ ) and significantly higher than $50 \%\left(\mathrm{t}_{(22,1)}=9.5, p<.001\right)$, indicating that both the celebrity and the non-famous females were perceived as being more attractive females than average.

All famous faces received likeability ratings above $50 \%\left(\mathrm{M}=66 \%\right.$, s.d. $=8.8 ; \mathrm{t}_{(17,1)}=$ $7.7, p<.001$ ) so no aversive reactions toward the presentation of celebrities were expected. Postscan measures on familiarity revealed that only in $1 \%$ of the total number of trials subjects did not recognize a celebrity as being famous or incorrectly perceived a non-famous face as being famous. Trials containing incorrectly judged famous or non-famous faces were removed from further behavioral analysis. However, as only few faces were incorrectly perceived as being famous or non-famous, trials containing these faces were not removed from the data used for brain analysis.

Fame did not affect response times of the responses given in the orientation task performed during scanning: subjects responded equally fast when indicating whether the presented female was the owner of a shoe if the presented female was a celebrity or a non-famous person $\left(\mathrm{t}_{(22,1)}=.93, p=.36\right)$. In addition, we checked the effects of fame on the responses given in the orientation task and found that subjects indicated that they less often thought a shoe was owned by a celebrity $(\mathrm{M}=40.5 \%$, s.d. $=8.5 \%)$ than by a non-famous female $(\mathrm{M}=51.9 \%$, s.d. $=$ $8.8 \%)\left(\mathrm{t}_{(22,1)}=7.9, p<.001\right)$. At first glance, this difference may seem surprising as the subjects were explicitly instructed that, on average, 50 percent of the shoes were truly owned by the female presented next to the shoe. However, this result supports our hypothesis that subjects indeed have more associations linked to a famous than to a non-famous face: The more knowledge subjects have about a person (in our case, a celebrity), the less often they think a particular shoe matches with this person.

\section{Effect of fame on recognition memory}

Recognition memory performance remained clearly above chance level as the overall proportion of hits (hits $/$ (hits + misses) $* 100=49.8 \%$, s.d. $=13.5 \%$ ) was significantly larger than the proportion of false alarms (false alarms / (false alarms + correct rejections) * $100=25.5 \%$, s.d. $=12.4 \%)$ in the post-scan recognition memory test $\left(\mathrm{t}_{(22,1)}=15.8, p<.001, \mathrm{M}_{\text {Recognition performance }}\right.$ $=24.3 \%$, s.d. $=7.7 \%$ ). As expected, subjects demonstrated better memory for shoes presented in combination with a famous face $(\mathrm{M}=28.6 \%$, s.d. $=1.0 \%)$ than with a non-famous face $(\mathrm{M}=$ 
$19.9 \%$, s.d. $=7.0 \%)\left(\mathrm{t}_{(22,1)}=5.5, p<.001\right)$. This is in line with results observed in earlier studies showing that celebrity endorsers have a positive effect on product memory (e.g. Friedman and Friedman, 1979; Petty et al., 1983).

\section{Effect of fame on purchase intention}

Contrary to our expectations, post-scan scores on purchase intention were not significantly different for shoes presented together with a famous face $(\mathrm{M}=40.1 \%$, s.d. $=8.4 \%)$ and shoes that were presented in combination with an non-famous face $(\mathrm{M}=39.9 \%$, s.d. $=8.1 \%)$ $\left(\mathrm{t}_{(22,1)}=-0.3, p=.79\right)$. However, fame did affect the purchase intention if shoes were categorized based on the responses that were given in the orientation task during scanning. Shoes of which subjects indicated they were not owned, received higher purchase intentions if they were presented together with a celebrity $(M=36.4 \%$, s.d. $=8.6 \%)$ than when they were shown with a non-famous female $(\mathrm{M}=34.6 \%$, s.d. $=8.8 \%)\left(\mathrm{t}_{(22,1)}=-2.1, p=.05\right)$. This result shows that only the shoes that were not perceived as being owned received a higher explicit purchase intention after initial presentation in a context of fame.

\section{2 fMRI results}

All neuroimaging results are presented in Table 1.

\section{The effect of fame on product processing}

When analyzing brain responses time-locked to the presentation of a shoe next to a face, we found differential activity in the medial part of the right orbitofrontal cortex between shoes presented with a famous face and shoes presented with a non-famous face (Shoe with Celebrity Face $>$ Shoe with non-Famous Face) (see figure 2). Masking this result with an exclusive mask that was generated of the Face contrast map (Celebrity Face > non-Famous Face) did not change the activity found in the medial orbitofrontal cortex. This supported the conclusion that activity in this area was related to the learning of associations between a famous face and a product and that it was not related to the processing of faces alone as the areas in which activity was related to the processing of faces were excluded in this analysis after masking.

\section{The effect of fame on face processing}

To reveal brain activity related to the processing of a celebrity face, we analyzed the data time-locked to the onset of the trial presenting a face together with a name. Contrasting the trials in which the face and name of a celebrity was shown with trials in which the face and name of a 
non-famous female were shown revealed significant activations in brain areas associated with the retrieval of episodic [the angular gyrus, precuneus and medial prefrontal cortex] (Maguire, 2001; Wagner et al., 2005) and semantic [the superior frontal area and middle temporal gyrus] knowledge (Simons and Spiers, 2003; Wiggs et al., 1999) (see figure 3). All activations in this contrast appear to be predominantly lateralized in the left hemisphere, a pattern typical for semantic memory-related activity (Mummery et al., 1999).

We did not find any activation in the medial temporal lobe, a region typically involved in the retrieval of episodic memories (Burgess et al., 2002). This suggests that either the explicit memories related to the famous face were well consolidated in prefrontal areas and retrieved independently of the medial temporal lobe (Takashima et al., 2006) or the memories were not vivid (Ryan et al., 2001) or associative enough (Eldridge et al., 2000) to increase activity in this area. In addition, the processing of famous faces did not activate the striatum or any other brain regions related to the processing of rewards. Apparently, the passive viewing of celebrities was not experienced as more rewarding than viewing equally attractive non-famous faces, indicating that earlier exposures to the celebrities did not influence subjects' affective response towards these celebrities.

\section{The effect of fame on purchase intent for not-owned shoes}

Behavioral results showed that purchase intention was enhanced by fame if subjects thought that a celebrity or non-famous attractive female did not own the shoes. However, contrasting the condition Not-owned Shoes with Celebrity Face with the condition Not-owned Shoes with non-Famous Face did not reveal any significant neural activations. This null finding is likely due to a lack of statistical power because of the reduced number of relevant trials per condition (only the not-owned trials were included).

\section{Discussion}

The results of our study are consistent with the general finding that celebrities are more effective endorsers than non-famous individuals. The enhanced memory performance for items that were encoded in the context of a famous individual can neither be explained by increased attractiveness of the celebrity nor by a higher level of perceived expertise, but only by the persuasiveness of fame itself. As predicted, we observed increased activity in the orbitofrontal cortex during the encoding of celebrity-product pairings. This result provides strong support for the idea that the mechanism underlying celebrity endorsement is a transfer of positive affect from

celebrity to product as the orbitofrontal cortex has been suggested to be important for the learning 
of associations between neutral and valenced stimuli (Rolls and Grabenhorst, 2008). In particular, we found enhanced activity in the medial part of the orbitofrontal cortex, which supports the hypothesis that celebrities give rise to positive emotions as the medial orbitofrontal cortex has consistently been associated with the encoding of the subjective liking of stimuli (Beer et al., 2008; Grabenhorst et al., 2008; Plassmann et al., 2008; Rolls et al., 2009). Although, the orbitofrontal cortex has been shown to respond to beautiful faces (Ishai, 2007; O'Doherty et al., 2003), the activity in the present study is unlikely to represent the reward activity related to the physical attractiveness of the famous faces, as the famous and non-famous faces included in our fMRI experiment were rated as equally physically attractive.

In addition, we performed an exclusive masking analysis to investigate whether the activity underlying the processing of products in the context of a famous face differed from the activity underlying the perception of a famous face alone. This analysis showed that the brain areas activated by passively viewing famous faces were not significantly activated during the trials in which a famous face was shown in combination with a product. In other words, the medial orbitofrontal cortex did not simply process the presence of a famous face during the presentation of celebrity-object pairings, but instead encoded the presentation of an object in the context of fame. Overall, our results support the hypothesis that the neural activity found in the medial orbitofrontal cortex represents a transfer of affect from celebrity to product.

\section{Memory retrieval and attention}

The present study predicted that the positive affect induced by a celebrity endorser could result from the retrieval of explicit and/or implicit knowledge. Investigation of the neural activity underlying the processing of a famous face showed increased activation in brain areas commonly involved during semantic and episodic retrieval tasks. This indicates that the perception of a celebrity face results in the retrieval of explicit memories. Interestingly, we did not find any evidence for the retrieval of implicit memories as there was no increase in neural activity in areas associated with the processing of reward when contrasting famous faces with non-famous faces. We only found activity in a reward-related region, the medial orbitofrontal cortex, during the presentation of a famous face together with an object. The medial orbitofrontal cortex was not activated during the presentation of a famous face alone, which suggests that the medial orbitofrontal cortex did not encode the positive affect associated with the retrieval of implicit memories related to a famous face, but instead represented the learning of associations between an initially neutral product and a positively valenced face. 
The idea that explicit memories are retrieved during the perception of a celebrity endorser is supported by the behavioral responses subjects gave during the orientation task in the scanner. In this task, we found that subjects less often thought that a shoe was owned by a celebrity than by a non-famous female. In light of the present imaging results this makes sense: the more subjects knew about a female whose face was presented, the less likely they found a shoe to match this female. Furthermore, the spontaneous retrieval of memories during exposure to famous faces is in line with the general idea that well-known persons produce automatic retrieval of person-identity information from long-term memory (Bruce and Young, 1986).

The present results have important practical implications for advertisers as they show that the retrieval of explicit memories is of central importance to the persuasiveness of celebrity endorsers. Advertisers may use this information and design celebrity advertisements more effectively by facilitating consumers in the retrieval of explicit positive memories (e.g. by adding names of popular movies featuring the endorser).

In the current study, the persuasiveness of celebrities did not depend on arousal-drivenattention. The processing of famous and non-famous faces did not evoke differential neural activity in attention-modulated areas such as the visual or inferotemporal cortex and reaction times on the orientation task were equal for both famous and non-famous conditions. This result seems to be in contradiction with the finding of Pleyers and colleagues (in press), who showed that a decrease in attention has a negative effect on the learning of associations between products and positively valenced stimuli. However, in the present study subjects were performing a task in the scanner that was explicitly designed to prevent them from losing attention during the lengthy experiment. Therefore, subjects probably paid equal attention to trials mimicking celebrity endorsements and trials presenting non-famous endorser. Nevertheless, the absence of attentional effects in the present imitation of celebrity endorsement implies that enhanced attention is not essential for celebrity advertisements to be effective.

\section{Purchase intention}

In the current study, purchase intentions were not higher for products presented in the context of fame than for products associated with an unknown female. In contrast to the study on celebrity expertise by Klucharev and colleagues (2008), our results show that a single exposure to a celebrity-product pairing was insufficient to affect explicit attitudes. Our imaging results suggest, however, that during this single exposure, positive affect is transferred from the celebrity to the product as activity in the medial orbitofrontal cortex is enhanced during the presentation of a product in the context of fame. The fact that we found an effect of fame on the brain but not on 
subjects' attitudes indicates that fame does increase the liking of objects but that this effect is too small to measure at the explicit level. This interpretation is important for consumer researchers as it suggests that the absence of significant changes in explicit purchase intention measures does not necessarily imply that the liking of a product is unaffected by the experimental manipulation.

Finally, there was one other interesting effect in the present behavioral results that deserves further attention. Although fame did not affect the purchase intention of all shoes presented, fame did affect the purchase intention if shoes were categorized based on the responses that were given in the orientation task during scanning. Shoes of which subjects indicated they were not owned, received higher purchase intentions if they were presented together with a celebrity than when they were shown with a non-famous female. This result indicates that only the shoes that were not perceived as being owned by a more-than-average-attractive female (recall that both famous and non-famous faces received attractiveness ratings higher than 50\%), received a higher explicit purchase intention after initial presentation in a famous context. It appears that a context of fame during encoding works particularly persuasive for products that subjects regarded as part of their consideration set, i.e. items that are not specifically associated with almost physically perfect models but instead can be owned by individuals like the subjects themselves.

To summarize, we have shown that the encoding of an object in the context of fame elicits activation in the medial orbitofrontal cortex. This result supports the hypothesis that, during celebrity endorsement, positive affect is transferred from presenter to product. Our research clearly demonstrated that this positive affect originates from the retrieval of semantic and episodic memories as brain regions implicated in the retrieval of explicit memories were activated during celebrity face perception. Furthermore, our results suggest that neither attentional processing nor the retrieval of implicit memories is required for a celebrity advertisement to be effective. Future studies should investigate whether the observed mechanism underlying the persuasive effect of fame can be generalized to the male population. 


\section{References}

Aharon, I., Etcoff, N., Ariely, D., Chabris, C.F., O'Connor, E., Breiter, H.C., 2001. Beautiful faces have variable reward value: fMRI and behavioral evidence. Neuron 32, 3, 537-551.

Beer, J.S., Stallen, M., Lombardo, M.V., Gonsalkorale, K., Cunningham, W.A., Sherman, J.W., 2008. The quadruple process model approach to examining the neural underpinnings of prejudice. NeuroImage 43, 4, 775-783.

Belk, R.W., 2003. Shoes and Self. Advances in Consumer Research 30, 1, 27-33.

Bradley, M.M., Greenwald, M.K., Petry, M.C., Lang, P.J., 1992. Remembering pictures: Pleasure and arousal in memory. Journal of Experimental Psychology: Learning, Memory, and Cognition 18, 2, 379-390.

Bruce, V., Young, A., 1986. Understanding face recognition. Br J Psychol 77 ( Pt 3), 305-327.

Burgess, N., Maguire, E.A., O'Keefe, J., 2002. The human hippocampus and spatial and episodic memory. Neuron 35, 4, 625-641.

Eldridge, L.L., Knowlton, B.J., Furmanski, C.S., Bookheimer, S.Y., Engel, S.A., 2000. Remembering episodes: a selective role for the hippocampus during retrieval. Nature Neuroscience 3, 11, 1149-1152.

Erdogan, B.Z., 1999. Celebrity Endorsement: A Literature Review. Journal of Marketing Management 15, 4, 291-314.

Friedman, H.H., Friedman, L., 1979. Endorser effectiveness by product type. Journal of Advertising Research 19, 63-71.

Grabenhorst, F., Rolls, E.T., Parris, B.A., 2008. From affective value to decision-making in the prefrontal cortex. European Journal of Neuroscience 28, 9, 1930-1939.

Harmon-Jones, E., Allen, J.J.B., 2001. The Role of Affect in the Mere Exposure Effect: Evidence from Psychophysiological and Individual Differences Approaches. Personality and Social Psychology Bulletin 27, 7, 889-898.

Heath, T.B., McCarthy, M.S., Mothersbaugh, D.L., 1994. Spokesperson Fame and Vividness Effects in the Context of Issue-Relevant Thinking: The Moderating Role of Competitive Setting. Journal of Consumer Research 20, 4, 520-534.

Ishai, A., 2007. Sex, beauty and the orbitofrontal cortex. International Journal of Psychophysiology 63, 2, 181-185.

Kamins, M.A., Brand, M.J., Hoeke, S.A., Moe, J.C., 1989. Two-Sided versus One-Sided Celebrity Endorsements: The Impact on Advertising Effectiveness and Effectiveness and Credibility. Journal of Advertising 18, 4-10. 
Kampe, K.K., Frith, C.D., Dolan, R.J., Frith, U., 2001. Reward value of attractiveness and gaze. Nature 413, 6856, 589.

Kanwisher, N., Wojciulik, E., 2000. Visual attention: insights from brain imaging. Nature Reviews 1, 2, 91-100.

Klucharev, V., Smidts, A., Fernández, G., 2008. Brain mechanisms of persuasive communication: How “Expert Power” modulates memory and attitudes. Social Cognitive and Affective Neuroscience 3, 353-366.

Kringelbach, M.L., 2005. The human orbitofrontal cortex: linking reward to hedonic experience. Nature Reviews Neuroscience 6, 9, 691-702.

Kringelbach, M.L., Rolls, E.T., 2004. The functional neuroanatomy of the human orbitofrontal cortex: evidence from neuroimaging and neuropsychology. Progress in Neurobiology 72, 5, 341-372.

LaBar, K.S., Mesulam, M.M., Gitelman, D.R., Weintraub, S., 2000. Emotional curiosity: modulation of visuospatial attention by arousal is preserved in aging and early-stage Alzheimer's disease. Neuropsychologia 38, 13, 1734-1740.

Maguire, E.A., 2001. Neuroimaging studies of autobiographical event memory. Philosophical transactions of the Royal Society of London 356, 1413, 1441-1451.

Mummery, C.J., Patterson, K., Wise, R.J.S., Vandenbergh, R., Price, C.J., Hodges, J.R., 1999. Disrupted temporal lobe connections in semantic dementia. Brain 122, 1, 61-73.

O'Doherty, J., Winston, J., Critchley, H., Perrett, D., Burt, D.M., Dolan, R.J., 2003. Beauty in a smile: the role of medial orbitofrontal cortex in facial attractiveness. Neuropsychologia 41, 2, 147-155.

Ohanian, R., 1991. The impact of celebrity spokespersons’ perceived image on consumers' intention to purchase. Journal of Advertising Research 31, 46-54.

Petty, R.E., Cacioppo, J.T., Schumann, D., 1983. Central and Peripheral Routes to Advertising Effectiveness: The Moderating Role of Involvement. Journal of Consumer Research 10, 2, 135 146.

Plassmann, H., O'Doherty, J., Shiv, B., Rangel, A., 2008. Marketing actions can modulate neural representations of experienced pleasantness. Proceedings of the National Academy of Sciences of the United States of America 105, 3, 1050-1054.

Pleyers, G., Corneille, O., Yzerbyt, V., Luminet, O., in press. Evaluative conditioning may incur attentional costs. Journal of Experimental Psychology: Animal Behavior Processes.

Pringle, H., Binet, L., 2005. How marketers can use celebrities to sell more effectively. Journal of Consumer Behaviour 4, 3, 201-214.

Rolls, E.T., Grabenhorst, F., 2008. The orbitofrontal cortex and beyond: from affect to decision-making. Progress in Neurobiology 86, 3, 216-244. 
Rolls, E.T., Grabenhorst, F., Parris, B.A., 2009. Neural Systems Underlying Decisions about Affective Odors. Journal of Cognitive Neuroscience (forthcoming).

Rossiter, J.R., Smidts, A., in review. The 'hook' theory of presenter characteristics explains persuasion and dissuasion of celebrity presenters. Working paper, Rotterdam School of Management, Erasmus University.

Russell, J.A., 1980. A circumplex model of affect. Journal of Personality and Social Psychology 39, 6, 1161-1178.

Ryan, L., Nadel, L., Keil, K., Putnam, K., Schnyer, D., Trouard, T., Moscovitch, M., 2001. Hippocampal complex and retrieval of recent and very remote autobiographical memories: Evidence from functional magnetic resonance imaging in neurologically intact people. Hippocampus 11, 6, 707-714.

Schacter, D.L., 1987. Implicit memory: history and current status. Journal of Experimental Psychology 13, 3, 501-518.

Schacter, D.L., Buckner, R.L., 1998. Priming and the Brain. Neuron 20, 2, 185-195.

Simons, J.S., Spiers, H.J., 2003. Prefrontal and medial temporal lobe interactions in long-term memory. Nature Reviews 4, 8, 637-648.

Takashima, A., Petersson, K.M., Rutters, F., Tendolkar, I., Jensen, O., Zwarts, M.J., McNaughton, B.L., Fernandez, G., 2006. Declarative memory consolidation in humans: a prospective functional magnetic resonance imaging study. Proceedings of the National Academy of Sciences of the United States of America 103, 3, 756-761.

Till, B.D., Stanley, S.M., Priluck, R., 2008. Classical Conditioning and Celebrity Endorsers: An Examination of Belongingness and Resistance to Extinction. Psychology \& Marketing 25, 2, 179-196.

Tulving, E., 1972. Episodic and Semantic Memory In: Tulving, E., Donaldson, W. (Eds.), Organization of Memory. Academic Press, New York. pp. 381-403.

Wagner, A.D., Shannon, B.J., Kahn, I., Buckner, R.L., 2005. Parietal lobe contributions to episodic memory retrieval. Trends in Cognitive Sciences 9, 9, 445-453.

Walther, E., Nagengast, B., Trasselli, C., 2005. Evaluative Conditioning in Social Psychology: Facts and Speculations. Cognition \& Emotion 19, 175-196.

Wiggs, C.L., Weisberg, J., Martin, A., 1999. Neural correlates of semantic and episodic memory retrieval. Neuropsychologia 37, 1, 103-118.

Zajonc, R.B., 2001. Mere Exposure: A Gateway to the Subliminal. Current Directions in Psychological Science 10, 6, 224-228. 


\section{Figures and Tables}

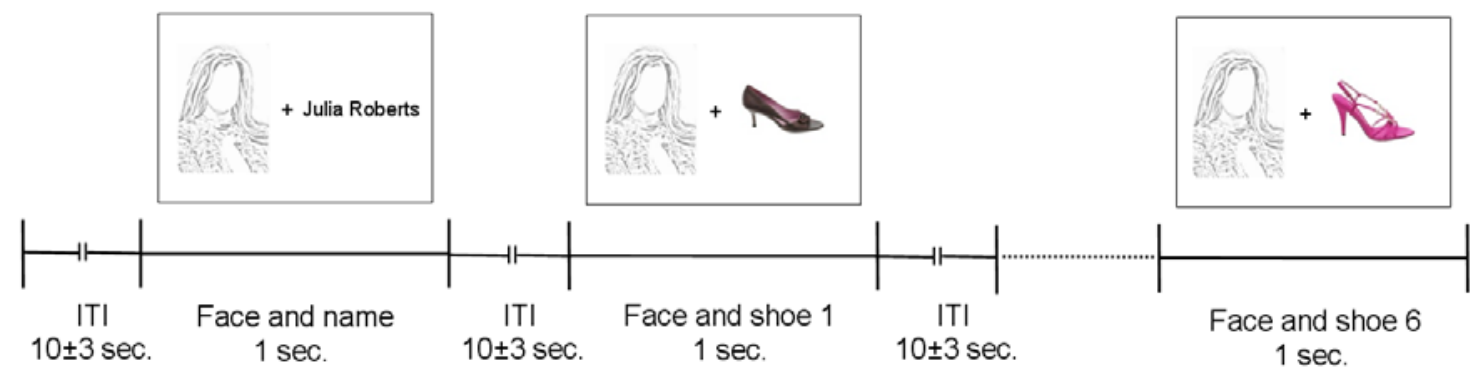

Fig. 1. Temporal layout of the stimulus presentation in the fMRI task. Shown here is a block of trials with a female celebrity. During the first trial of each block a female face was presented together with a name. At the 6 following trials the face was paired with a shoe. Subjects were instructed to indicate whether or not they thought this shoe was owned by the female whose face was presented next to the shoe. All trials were separated by a varying intertrial interval (ITI). In this figure a sketch of a celebrity is presented instead of a real photo as used in the study, due to potential copyright restrictions. 
Table 1. Significant areas of activation associated with the effect of fame on product processing (Shoes with Celebrity face $>$ Shoes with non-Famous face) and on face processing (Celebrity face $>$ non-Famous face).

Brain region

$$
\begin{array}{llllll}
\text { HEM } & \mathrm{x} & \mathrm{y} & \mathrm{z} & \text { Nr. of voxels } & \begin{array}{c}
\mathrm{z} \text { score } \\
(\max )
\end{array}
\end{array}
$$

Shoes with Celebrity Face > Shoes with non-Famous Face

$\begin{array}{llllll}\text { Medial orbitofrontal cortex, } & \mathrm{R} & 6 & 46 & -16\end{array}$

343

4.8

BA 11

Celebrity Face > non-Famous Face

Anterior cingulate cortex, BA L

$\begin{array}{llll}-8 & 48 & 0 & 625\end{array}$

5.0

10

Superior frontal area, BA 9

$\begin{array}{llll}\mathrm{L} & -18 & 38 & 48\end{array}$

612

4.9

Precuneus

$\begin{array}{llll}\mathrm{L} & -8 & -58 & 32\end{array}$

696

4.7

Angular gyrus, BA 39

L $\quad-44 \quad-62 \quad 38$

1070

4.6

Middle temporal gyrus, BA 21

L

$\begin{array}{lll}-56 & -44 & -2\end{array}$

609

4.1 


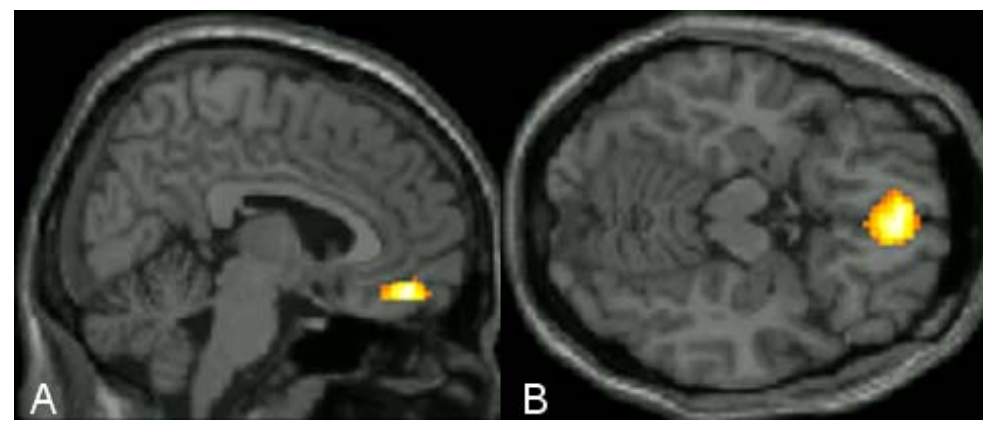

Fig. 2. Brain map showing the medial orbitofrontal cortex involved in the processing of products in the context of fame (Shoe with Celebrity Face $>$ Shoe with non-Famous Face), $p<.001$ uncorrected, (A) $\mathrm{x}=6$; (B) $\mathrm{z}=-16$ 


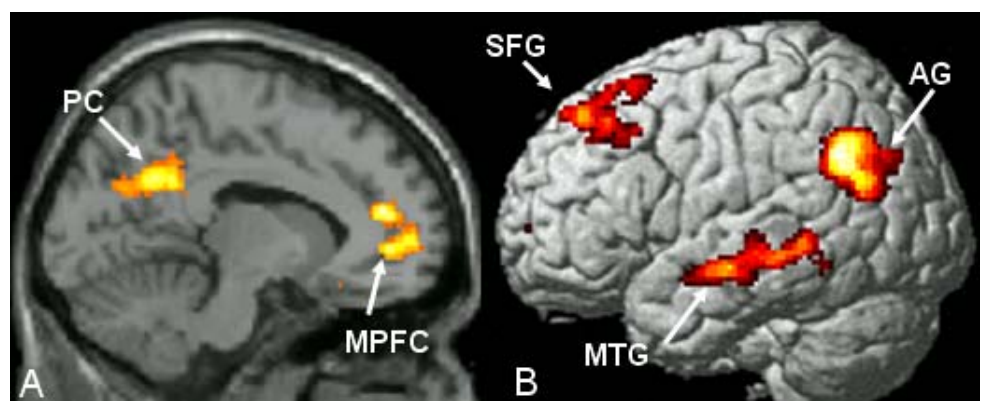

Fig. 3. Brain regions involved in the processing of famous faces (Celebrity Face $>$ non-Famous Face), $\mathrm{p}<.001$ uncorrected. (A) Medial view of the left hemisphere (parasagittal slice): PC = Precuneus; $\mathrm{MPFC}=$ Medial prefrontal cortex; $\mathrm{x}=-8$. (B) Lateral view of the left hemisphere (3D reconstruction): SFG = Superior frontal gyrus; $\mathrm{AG}=$ Angular gyrus; $\mathrm{MTG}=$ Middle temporal gyrus 


\title{
Publications in the Report Series Research ${ }^{*}$ in Management
}

\section{ERIM Research Program: "Marketing"}

2009

Map Based Visualization of Product Catalogs

Martijn Kagie, Michiel van Wezel, and Patrick J.F. Groenen

ERS-2009-010-MKT

http://hdl.handle.net/1765/15142

Embedding the Organizational Culture Profile into Schwartz's Universal Value Theory using Multidimensional Scaling with Regional Restrictions

Ingwer Borg, Patrick J.F. Groenen, Karen A. Jehn, Wolfgang Bilsky, and Shalom H. Schwartz

ERS-2009-017-MKT

http://hdl.handle.net/1765/15404

Determination of Attribute Weights for Recommender Systems Based on Product Popularity

Martijn Kagie, Michiel van Wezel, and Patrick J.F. Groenen

ERS-2009-022-MKT

http://hdl.handle.net/1765/15910

An Empirical Comparison of Dissimilarity Measures for Recommender Systems

Martijn Kagie, Michiel van Wezel, and Patrick J.F. Groenen

ERS-2009-023-MKT

http://hdl.handle.net/1765/15911

\begin{abstract}
A Viral Branching Model for Predicting the Spread of Electronic Word-of-Mouth Ralf van der Lans, Gerrit van Bruggen, Jehoshua Eliashberg, Berend Wierenga ERS-2009-029-MKT

http://hdl.handle.net/1765/16015
\end{abstract}

Celebrities and Shoes on the Female Brain: The Neural Correlates of Product Evaluation in the Context of Fame Mirre Stallen, Ale Smidts, Mark Rijpkema, Gitty Smit, Vasily Klucharev, and Guillén Fernández ERS-2009-048-MKT

http://hdl.handle.net/1765/16583

A complete overview of the ERIM Report Series Research in Management: https://ep.eur.nl/handle/1765/1

ERIM Research Programs:

LIS Business Processes, Logistics and Information Systems

ORG Organizing for Performance

MKT Marketing

F\&A Finance and Accounting

STR Strategy and Entrepreneurship 